Part of Journal of Research of the National Bureau of Standards, Volume 23, September 1939

\title{
COMPARISON OF ACCELERATED AGING OF RECORD PAPERS WITH NORMAL AGING FOR 8 YEARS
}

\author{
By B. W. Scribner
}

\section{ABSTRAC'T}

Various grades of record papers that had been stored under normal conditions for 8 years were tested and the results are compared with test values for their original properties and their properties after accelerated aging by heat at time of storage. The results agree well with a retest made after 4 years of normal aging. The papers had the same relative order of stability, as shown by retention of folding endurance, under both kinds of aging. Their stability was commensurate with the chemical purity of the papers, and the same kind of chemical changes occurred during 8 years of natural aging as under accelerated aging. The cellulose of the stable papers was in good condition, as indicated by high alpha-cellulose content, low copper number, and low or moderate acidity.

\section{CONTENTS}

I. Introduction $\ldots 405$

II. Test methods _...

III. Test data $\ldots \ldots \ldots \ldots$

IV. Discussion _. .

V. Summary

VI. References...........

\section{INTRODUCTION}

The results of an investigation at the National Bureau of Standards $[1],{ }^{1}$ in its early work relating to the standardization and classification of record papers, indicate that the relative stability of such papers under normal storage conditions can be determined satisfactorily by heating the papers and testing for decrease in strength and changes in certain chemical properties. The papers studied in that work were 37 commercial writing and book papers representative of the various grades as produced at the time. The test data showed a good correlation between the retention of folding endurance on heating the papers for 72 hours at $100^{\circ} \mathrm{C}$. and the chemical condition of the paper with respect to the purity of the cellulose, as indicated by alpha-cellulose content and copper number, the acidity, and the rosin content. The more stable papers under the heat test were characterized by a good condition of the cellulose as shown by a high alpha-cellulose content and a low copper number, by low acidity, and by low rosin content, although the last apparently was of minor importance. It was found that the papers could be grouped satisfactorily with respect to the degree of stability required for different record purposes by means of these physical and chemical data, and classifications of record papers based on such data have been proposed [2].

\footnotetext{
1 Numbers in brackets indicate the literature references at the end of the paper.
} 
To obtain further information, 33 of the papers mentioned were stored at the Bureau for testing at various periods of time to compare the effects of normal aging with the effects of aging accelerated by heating. The storage conditions are those of the average good business office practice, that is, the papers are not exposed to any abnormal conditions of temperature, humidity, or air pollution. The first retests of the papers were made after they had been stored for 4 years. The papers were tested for strength, alpha-cellulose, copper number, and acidity, and despite the short period of aging, the grading of the papers for stability was very similar to that foretold by the accelerated aging [3]. The following is an account of retests of the stored papers after 8 years of aging.

\section{TEST METHODS}

As in the first retest of the papers, they were tested again for folding endurance, acidity (Kohler-Hall), alpha-cellulose, and copper number. These tests were made by the present methods of the Technical Association of the Pulp and Paper Industry, ${ }^{2}$ which yield values comparable with those originally obtained for the papers. (In considering the results of the folding endurance tests, papers having very low values should not be regarded as being actually brittle, as the test strips are folded under a tension of $1 \mathrm{~kg}$, therefore, such papers may still be in a serviceable condition.) In addition, tests were made for acidity in terms of $\mathrm{pH}$, beta-cellulose, and gamma-cellulose. Suitable methods for these tests were not available when the papers were previously tested. With development of satisfactory technique and equipment for the determination of $\mathrm{pH}$, this has now become the preferred way of expressing the acidity of paper. The procedure employing hot extraction of paper with water, which is specified in the present method of the Technical Association of the Pulp and Paper Industry, and a cold-extraction method developed by H. F. Launer [4] were used. The latter method appears to be preferable, and its adoption is being considered by the Technical Association. The cellulose fractions were determined by a modified volumetric procedure, also developed by Launer, in which oxidation by dichromate is used [5]. Satisfactory determination of the beta and gamma fractions cannot always be made by gravimetric procedures, and the volumetric method has several other advantages.

\section{TEST DATA}

Descriptions of the papers and the test data are given in table 1. For additional information on the papers, see reference [1]. There are no data given herein for samples 104, 113, 122, 115, 148 (corresponding to Nos. 1, 2, 20, 24 and 32 in fig. 1) included in the previous work, as the supply of these had become exhausted. Sample 782, a paper made in the Bureau mill from purified wood fibers, was added to include a high-grade paper of this kind. The figure of 55-percent retention of folding endurance on heating previously reported for sample 118 appears to be in error on consideration of the general good quality of this paper, and a retest made at this time yielded a figure of 76 percent. Therefore, this latter value is given in this report.

2 Copies can be obtained from the Association at 122 East 42d Street, New York, N. Y. 
TABLE 1.-Test data on paper

\begin{tabular}{|c|c|c|c|c|c|c|c|c|c|c|c|c|c|c|c|c|c|c|c|c|c|c|c|c|c|}
\hline \multirow{4}{*}{$\begin{array}{l}\text { Numbers in this } \\
\text { column refer to } \\
\text { the numbers in } \\
\text { figures } 1 \text { and } 2\end{array}$} & & \multicolumn{3}{|c|}{ Kind of fiber } & \multicolumn{12}{|c|}{ Original tests } & \multicolumn{9}{|c|}{ Tests after 8 years of normal aging } \\
\hline & \multirow[b]{3}{*}{ 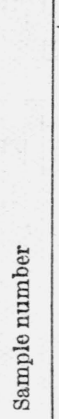 } & \multirow[b]{3}{*}{ 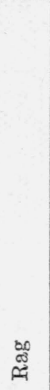 } & \multicolumn{2}{|c|}{$\begin{array}{c}\text { Chemical } \\
\text { wood }\end{array}$} & \multicolumn{8}{|c|}{ Before heat treatment } & \multicolumn{4}{|c|}{$\begin{array}{l}\text { After heating sample at } \\
100^{\circ} \mathrm{C} \text { for } 72 \text { hours }\end{array}$} & \multirow{3}{*}{ 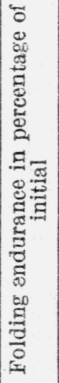 } & \multirow{3}{*}{ 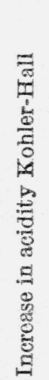 } & \multirow{3}{*}{ 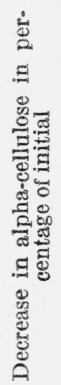 } & \multirow{3}{*}{ 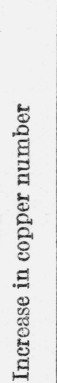 } & \multirow[b]{3}{*}{ 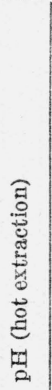 } & \multirow[b]{3}{*}{ 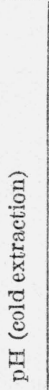 } & \multirow[b]{3}{*}{ 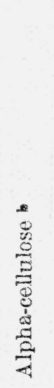 } & \multirow[b]{3}{*}{ 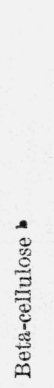 } & \multirow[b]{3}{*}{ 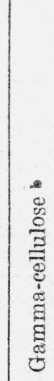 } \\
\hline & & & & & $\begin{array}{c}\mathrm{Fol} \\
\mathrm{d} u\end{array}$ & & & & & & & & 岕 & 㫕 & 总 & 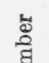 & & & & & & & & & \\
\hline & & & 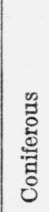 & 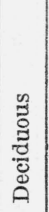 & 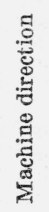 & 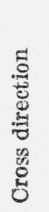 & क्न & 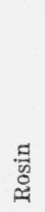 & है & 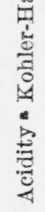 & 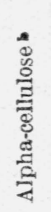 & 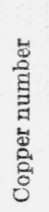 & 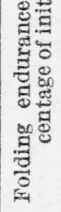 & 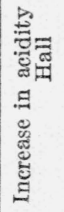 & 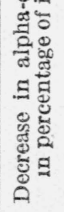 & 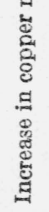 & & & & & & & & & \\
\hline
\end{tabular}

ALL-RAG PAPERS

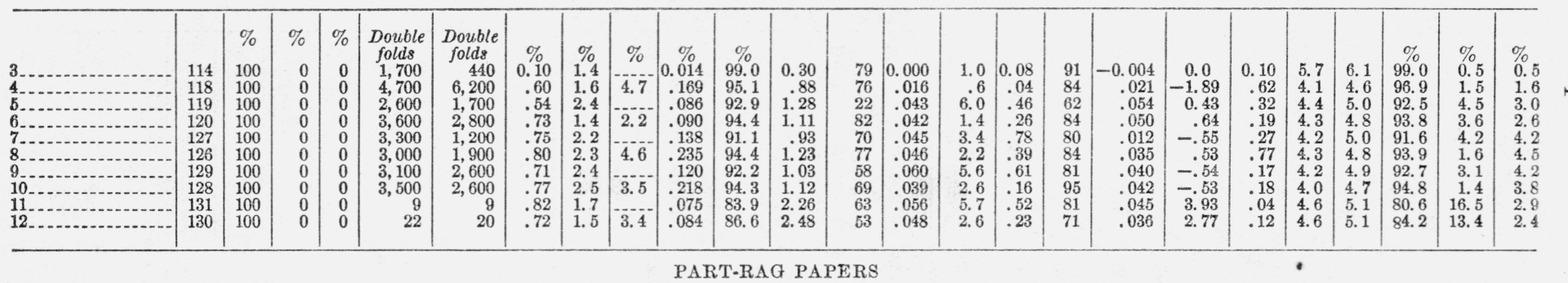

\begin{tabular}{|c|c|c|c|c|c|c|c|c|c|c|c|c|c|c|c|c|c|c|c|c|c|c|c|c|c|}
\hline 13 & 111 & 60 & 40 & 0 & 102 & 71 & 0.48 & 2.7 & & 0.076 & 82.0 & 3. 24 & 24 & 0.051 & 7.8 & 0.57 & 39 & 0.044 & 5.61 & 0.06 & 4.4 & 4.9 & 77.4 & 16.6 & 6.0 \\
\hline & 112 & 60 & 40 & 0 & 210 & 110 & .52 & 2.5 & 1.1 & .119 & 81.8 & 3. 39 & 16 & .043 & 6.3 & .42 & 28 & .021 & 4. 52 & -.09 & 4.3 & 4. 7 & 78.1 & 15.8 & 6.1 \\
\hline & 133 & 65 & 35 & 0 & 340 & 190 & .39 & 1. 6 & & .055 & 79.0 & 2.31 & 15 & .049 & 5.7 & 1,50 & 34 & .035 & 5.95 & 1.09 & 4.5 & 5.1 & 74.3 & 19.3 & 6.4 \\
\hline 16. & $\begin{array}{l}130 \\
132\end{array}$ & 65 & 35 & 0 & 340 & 220 & .43 & 1.5 & 1.1 & .079 & 80.2 & 3. 38 & 17 & .047 & 4.7 & .53 & 23 & .021 & 8. 59 & .12 & 4.5 & 5.2 & 74.3 & 20.0 & 5.7 \\
\hline
\end{tabular}


TABLE 1.-Test data on paper-Continued

\begin{tabular}{|c|c|c|c|c|c|c|c|c|c|c|c|c|c|c|c|c|c|c|c|c|c|c|c|c|c|}
\hline \multirow{4}{*}{$\begin{array}{l}\text { Numbers in this } \\
\text { column refer to } \\
\text { the numbers in } \\
\text { figures } 1 \text { and } 2\end{array}$} & \multirow[b]{4}{*}{ 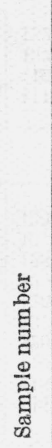 } & \multicolumn{3}{|c|}{ Kind of fiber } & \multicolumn{12}{|c|}{ Original tests } & \multicolumn{9}{|c|}{ Tests after 8 years of normal aging } \\
\hline & & \multirow[b]{3}{*}{ 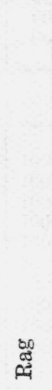 } & \multicolumn{2}{|c|}{$\begin{array}{c}\text { Chemical } \\
\text { wood }\end{array}$} & \multicolumn{8}{|c|}{ Before heat treatment } & \multicolumn{4}{|c|}{$\begin{array}{l}\text { After heating sample at } \\
100^{\circ} \mathrm{C} \text { for } 72 \text { hours }\end{array}$} & \multirow{3}{*}{ 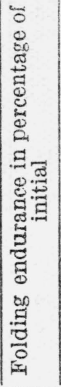 } & \multirow{3}{*}{ 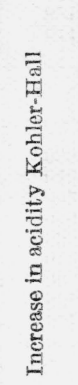 } & \multirow{3}{*}{ 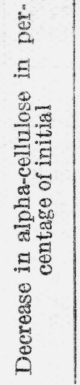 } & \multirow{3}{*}{ 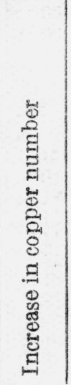 } & \multirow{3}{*}{ 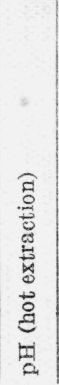 } & \multirow[b]{3}{*}{ 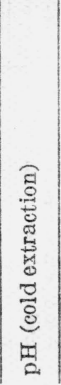 } & \multirow[b]{3}{*}{ 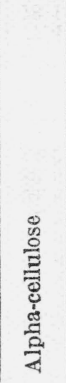 } & \multirow[b]{3}{*}{ 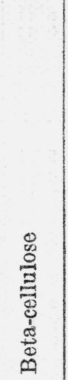 } & \multirow[b]{3}{*}{ 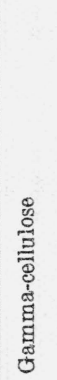 } \\
\hline & & & & & \multicolumn{2}{|c|}{$\begin{array}{l}\text { Folding en- } \\
\text { durance }\end{array}$} & & & & & & & $\stackrel{\dot{b}}{\mathrm{E}}$ & 它 & 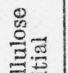 & 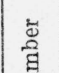 & & & & & & & & & \\
\hline & & & 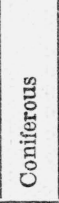 & 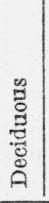 & 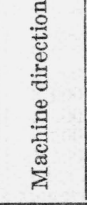 & 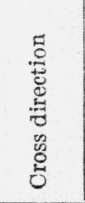 & 营 & 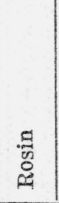 & $\stackrel{\Xi}{\overparen{Z}}$ & 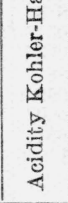 & 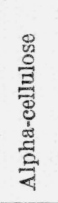 & 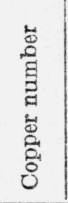 & 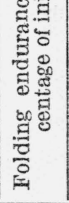 & 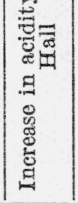 & 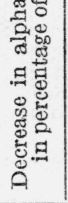 & 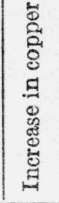 & & & & & & & & & \\
\hline \multicolumn{26}{|c|}{ PURIFIED WOOD FIBER PAPERS ० } \\
\hline $\begin{array}{ll}19-- \\
34-\end{array}$ & $\begin{array}{l}105 \\
106 \\
107 \\
782\end{array}$ & $\begin{array}{c}\% \\
0 \\
0 \\
0 \\
0\end{array}$ & \begin{tabular}{c|}
$\%$ \\
100 \\
100 \\
100 \\
100
\end{tabular} & $\begin{array}{r}\% \\
0 \\
0 \\
0 \\
0\end{array}$ & $\begin{array}{c}\text { Double } \\
\text { folds } \\
1,400 \\
2,500 \\
1,900 \\
4,400\end{array}$ & $\begin{array}{c}\text { Double } \\
\text { folds } \\
800 \\
1,600 \\
1,200 \\
5,500\end{array}$ & $\begin{array}{l}\% \\
0.34 \\
.51 \\
.39 \\
.42\end{array}$ & \begin{tabular}{l|}
$\%$ \\
1.4 \\
1.5 \\
1.2 \\
1.8
\end{tabular} & $\begin{array}{c}\% \\
2.7 \\
2.4 \\
2.2 \\
-\cdots\end{array}$ & $\begin{array}{c}\% \\
0.092 \\
.063 \\
.114 \\
.016\end{array}$ & $\begin{array}{l}\% \\
90.5 \\
88.8 \\
88.3 \\
90.5\end{array}$ & $\begin{array}{r}1.40 \\
1.37 \\
1.78 \\
.67\end{array}$ & $\begin{array}{l}54 \\
71 \\
56 \\
96\end{array}$ & $\left|\begin{array}{c}0.050 \\
.031 \\
.028 \\
\cdots\end{array}\right|$ & \begin{tabular}{r|}
1.1 \\
1.9 \\
1.9 \\
.4
\end{tabular} & $\begin{array}{r}0.32 \\
.35 \\
.20 \\
.14\end{array}$ & $\begin{array}{l}40 \\
52 \\
63 \\
91\end{array}$ & $\begin{array}{l}0.038 \\
.047 \\
.036 \\
.004\end{array}$ & $\begin{array}{l}0.55 \\
2.27 \\
1.36 \\
2.43\end{array}$ & $\begin{array}{l}0.10 \\
.43 \\
.12 \\
.10\end{array}$ & $\begin{array}{l}4.1 \\
4.5 \\
4.2 \\
5.2\end{array}$ & $\begin{array}{l}4.5 \\
5.1 \\
5.1 \\
6.1\end{array}$ & $\begin{array}{c}\% \\
90.0\end{array}$ & $\begin{array}{l}\% \\
2.5 \\
4.5 \\
5.3 \\
4.9\end{array}$ & $\begin{array}{l}\% \\
7.5 \\
8.7 \\
7.6 \\
6.8\end{array}$ \\
\hline \multicolumn{26}{|c|}{ SULFITE WOOD FIBER PAPERS } \\
\hline $\begin{array}{l}21 \\
22 \\
25 \\
26 \\
26 \\
28\end{array}$ & $\begin{array}{l}108 \\
109 \\
110 \\
116 \\
117 \\
134 \\
135\end{array}$ & $\begin{array}{l}0 \\
0 \\
0 \\
0 \\
0 \\
0 \\
0\end{array}$ & $\begin{array}{l}100 \\
100 \\
100 \\
100 \\
100 \\
100 \\
100\end{array}$ & $\begin{array}{l}0 \\
0 \\
0 \\
0 \\
0 \\
0 \\
0\end{array}$ & $\begin{array}{r}15 \\
49 \\
530 \\
500 \\
150 \\
510 \\
110\end{array}$ & \begin{tabular}{r|}
17 \\
22 \\
250 \\
360 \\
160 \\
190 \\
72
\end{tabular} & $\begin{array}{r}7.12 \\
1.06 \\
.60 \\
.51 \\
2.92 \\
.48 \\
6.12\end{array}$ & \begin{tabular}{l|}
2.2 \\
2.4 \\
2.8 \\
1.9 \\
1.4 \\
1.7 \\
2.0
\end{tabular} & 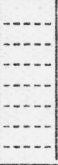 & $\begin{array}{l}0.108 \\
.084 \\
.113 \\
.119 \\
.033 \\
.082 \\
.066\end{array}$ & $\begin{array}{l}77.8 \\
77.2 \\
81.6 \\
76.4 \\
80.6 \\
79.9 \\
79.2\end{array}$ & $\begin{array}{l}4.89 \\
4.78 \\
3.77 \\
4.27 \\
2.98 \\
3.75 \\
3.29\end{array}$ & \begin{tabular}{r|r}
10 \\
9 \\
1 \\
3 \\
12 \\
1 \\
6
\end{tabular} & $\left|\begin{array}{l}0.056 \\
.071 \\
.014 \\
.075 \\
.023 \\
.058 \\
.031\end{array}\right|$ & $\begin{array}{l}5.7 \\
4.1 \\
5.9 \\
7.9 \\
4.3 \\
4.1 \\
4.1\end{array}$ & $\begin{array}{r}0.46 \\
.49 \\
.55 \\
.51 \\
.59 \\
.36 \\
.80\end{array}$ & $\begin{array}{r}16 \\
14 \\
14 \\
8 \\
29 \\
16 \\
21\end{array}$ & $\begin{array}{r}0.092 \\
.136 \\
.077 \\
.041 \\
.067 \\
.068 \\
.034\end{array}$ & $\begin{array}{l}7.58 \\
5.96 \\
3.06 \\
3.14 \\
1.61 \\
3.75 \\
2.02\end{array}$ & $\begin{array}{r}0.41 \\
.12 \\
.03 \\
.23 \\
-.18 \\
.15 \\
.31\end{array}$ & $\begin{array}{l}4.2 \\
4.3 \\
4.4 \\
4.4 \\
5.3 \\
4.3 \\
4.7\end{array}$ & $\begin{array}{l}4.9 \\
4.8 \\
4.7 \\
4.9 \\
5.4 \\
5.0 \\
5.0\end{array}$ & \begin{tabular}{|l|}
71.9 \\
72.6 \\
79.1 \\
74.0 \\
79.3 \\
76.9 \\
77.6
\end{tabular} & $\begin{array}{r}17.1 \\
16.7 \\
9.0 \\
12.6 \\
7.2 \\
10.5 \\
10.1\end{array}$ & $\begin{array}{l}11.0 \\
10.7 \\
11.9 \\
13.4 \\
13.5 \\
12.6 \\
12.3\end{array}$ \\
\hline \multicolumn{26}{|c|}{ SODA-SULFITE WOOD FIBER PAPERS } \\
\hline $\begin{array}{l}29 \\
30 \\
31 \\
33\end{array}$ & $\begin{array}{l}123 \\
124 \\
147 \\
152\end{array}$ & $\begin{array}{l}0 \\
0 \\
0 \\
0\end{array}$ & $\begin{array}{l}65 \\
50 \\
35 \\
25\end{array}$ & $\begin{array}{l}35 \\
50 \\
65 \\
75\end{array}$ & $\begin{array}{r}5 \\
2 \\
16 \\
9\end{array}$ & $\begin{array}{l}4 \\
2 \\
6 \\
7\end{array}$ & $\begin{array}{l}19.11 \\
19.99 \\
17.25 \\
15.55\end{array}$ & \begin{tabular}{|r|}
0.6 \\
.8 \\
.6 \\
1.1
\end{tabular} & \begin{tabular}{|c|} 
\\
$\cdots$ \\
\hdashline- \\
\hdashline$-\cdot$ \\
\end{tabular} & $\mid \begin{array}{l}0.085 \\
.095 \\
.038 \\
.031\end{array}$ & $\begin{array}{l}74.0 \\
63.8 \\
77.9 \\
78.8\end{array}$ & $\begin{array}{l}3.72 \\
5.19 \\
2.29 \\
2.55\end{array}$ & $\begin{array}{l}35 \\
48 \\
64 \\
69\end{array}$ & $\left|\begin{array}{r}0.072 \\
.067 \\
.010 \\
.011\end{array}\right|$ & $\begin{array}{r}6.8 \\
8.4 \\
.2 \\
.4\end{array}$ & $\begin{array}{r}0.40 \\
.19 \\
.06 \\
.10\end{array}$ & $\begin{array}{l}46 \\
50 \\
68 \\
75\end{array}$ & $\begin{array}{r}0.065 \\
.095 \\
.012 \\
.009\end{array}$ & $\begin{array}{r}14.73 \\
8.46 \\
1.28 \\
1.27\end{array}$ & $\begin{array}{r}0.68 \\
.41 \\
.41 \\
.05\end{array}$ & \begin{tabular}{|l|}
4.3 \\
4.4 \\
6.1 \\
5.9
\end{tabular} & $\begin{array}{l}5.0 \\
5.1 \\
6.5 \\
6.5\end{array}$ & \begin{tabular}{|l|}
63.1 \\
58.4 \\
76.9 \\
77.8
\end{tabular} & \begin{tabular}{|l|}
27.5 \\
31.5 \\
18.6 \\
16.7
\end{tabular} & $\begin{array}{r}9.4 \\
10.1 \\
4.5 \\
5.5\end{array}$ \\
\hline
\end{tabular}


Bursting strength, tensile strength, and tearing strength tests were made but the data are not included because, as found in the previous work, they appear to have no consistent relation to the weakening of paper on aging. The results of folding-endurance tests, however, agree very well with the degree of stability of paper indicated by its chemical characteristics.

\section{DISCUSSION}

In considering the relation of these test data to the stability of the papers, only fairly large differences in the values should be regarded as having much significance. One reason for this is that the papers are complex materials; they contain several components that may have a deteriorative effect and the interreaction of such components during the aging of the papers must be complicated. It is because of this that one cannot expect any one component to indicate closely how stable a paper will be. Another variable is introduced by the nonhomogeneous structure of paper. This affects the folding endurance particularly. It has been found that duplicate determinations of the folding endurance of a sample of paper may yield values differing as much as 25 percent or so, if the two sets of test strips are taken from separated areas of the sample [6]. The strips were so taken in this case because it was felt that a better indication of the condition of the sample as a whole would be thus obtained than if contiguous strips were taken. Surface sizing presents another complication. In a Bureau study of the manufacture of writing paper from rags, it was found that increased folding endurance imparted to paper by glue or starch surface sizing was generally largely lost in the heat test [7]. In the present report, the glue content reported is from surface sizing. However, despite these adverse influences on the accuracy of the indicated relative stability of these papers, very good agreement on the whole was obtained between the results from accelerated aging and those from normal aging, between the chemical condition of the papers and their stability, and between the retests made after the two periods of natural aging.

In figure 1 is shown the relation between the effects on folding endurance of heating the papers and of normal aging for 4 years and for 8 years. It will be noted that there is good agreement in the grouping of the papers according to their relative stability, as found by their retention of folding endurance after heating and after the two aging periods. As was to be expected, there was better agreement in this respect after the 8 years of natural aging than after the shorter period of 4 years, but the agreement, in general, between the results of the two aging periods is very good. On the whole, papers previously found to have a high retention of folding endurance showed little further loss of folding endurance during the additional 4 years of aging, but the opposite is true of the less stable papers. The comparison of the effects of normal aging for 8 years and of accelerated aging is shown in another way in figure 2 in order to bring out more effectively the good correlation between them.

Also, as was found in the previous retest, and as has been consistently found in the many other Bureau studies relating to the stability of papers, there is good correlation between certain chemical properties of the papers and their degree of stability. As has been 
mentioned before, a straight-line relationship between any one component of paper and its stability cannot be expected. Considering the papers as a whole, those having cellulose of good quality, as indicated by high alpha-cellulose and low copper number, and having a low or moderate degree of acidity proved to be the more stable papers. Of these two considerations, the condition of the cellulose appears to be of primary importance because generally the papers which contain very poor cellulose deteriorated rapidly, irrespective of the initial

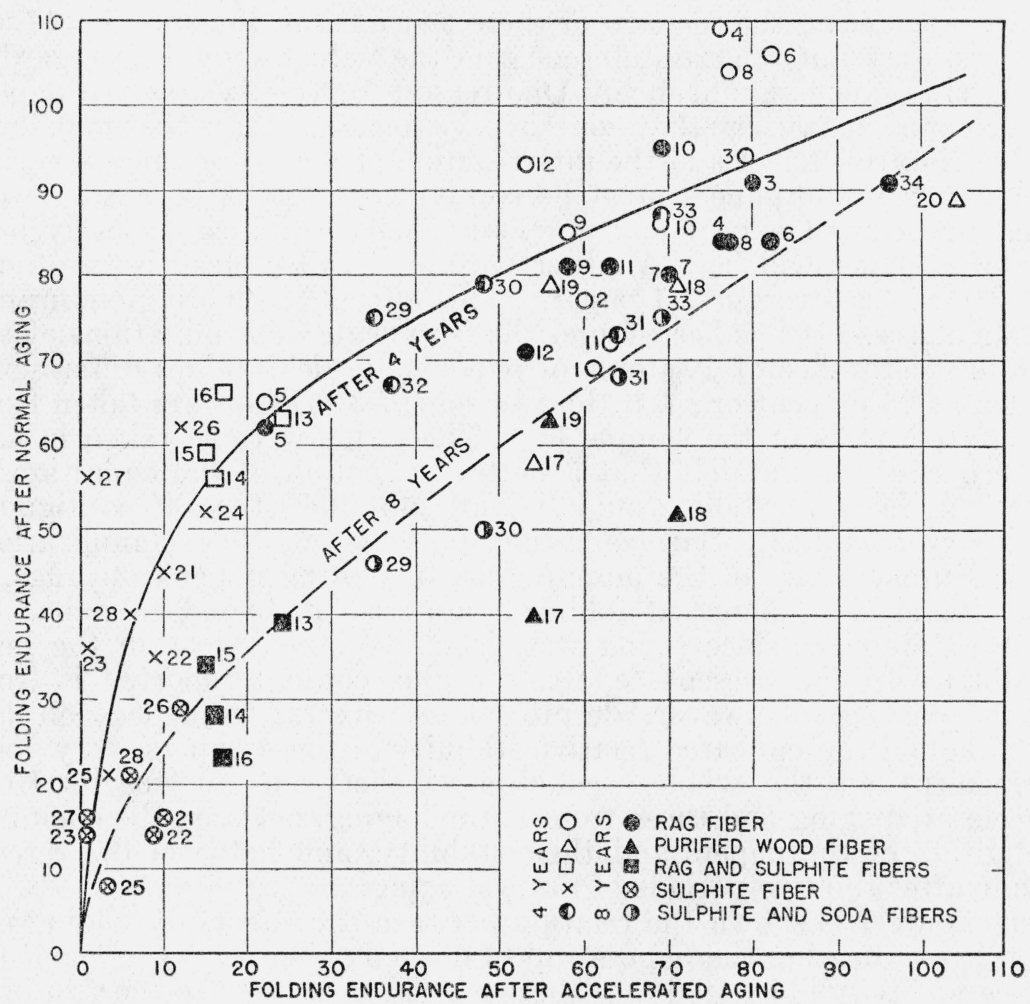

FIGURE 1.-Comparison of retention of folding endurance of papers after normal and accelerated aging, in percentage of initial.

The values for accelerated aging were obtained at the time the papers were stored, therefore, the figures for the 4-year and 8-year normal-aging periods bear a vertical straight-line relationship. No values are given for the 8-year period for samples $1,2,20,24$, and 32 as these had become exhausted. No value is given for the 4-year period for sample 34 as it was not tested at that time. The curves have no significance except to indicate the grouping of the papers. The accelerated aging consisted in heating for 72 hours at $100^{\circ} \mathrm{C}$.

acidity. As pointed out in the previous report, the papers made from soda and sulfite pulps have a better degree of stability than would be expected from consideration of the condition of the cellulose. This has been found to be true, in general, for papers containing soda pulp fibers. Such fibers are characterized by a high content of pentosans, which change very little under the heat test, and this may have some bearing on the stability of the fibers [8]. The rosin content of the papers is apparently of minor importance, as has been found in other studies. 


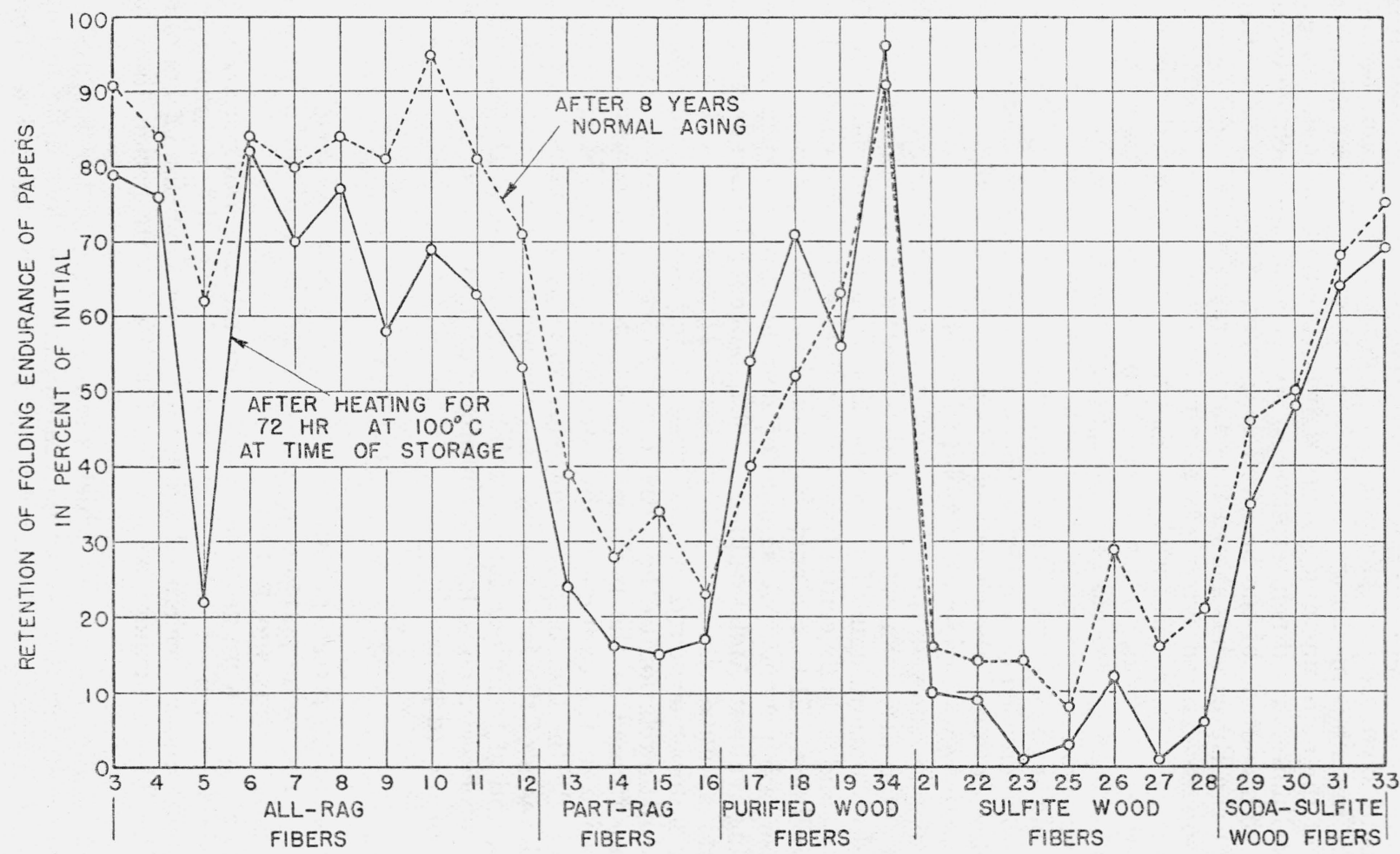

FIGURE 2.-Further comparison of retention of folding endurance of papers after normal and accelerated aging. 
Contrary to the findings at the end of the 4-year natural-aging period, at the end of the 8-year period the papers in many cases showed significant changes in alpha-cellulose, copper number, and acidity. These same kinds of changes took place under the accelerated aging. Many of the more unstable papers showed an appreciable decrease in alpha-cellulose, and it is interesting to note that such papers generally had a high content of the beta-cellulose fraction after aging. Other work at the Bureau has shown that the decrease in alpha-cellulose of papers on accelerated aging is largely reflected in an increase in betacellulose with little change in the gamma portion [9]. Also in this connection, the results of tests of some papers from books that were from 150 to 200 years old are of interest. Although the papers were apparently composed largely of linen fibers, which are very stable under good conditions, several of the papers were very brittle; they cracked apart when creased only a few times between the fingers. Apparently the deterioration of the papers had been caused by storage in a damp place, as there was evidence of mold, which is known to damage paper. These papers showed the same condition of cellulose found in the papers under discussion which had deteriorated considerably on heating and on natural aging for 8 years, that is, a low content of alphacellulose and a high content of beta-cellulose, typical values being alpha-cellulose, 51.0 percent; beta-cellulose, 44.5 percent; gammacellulose, 4.5 percent. A sample of new linen-fiber paper had the following values: Alpha-cellulose, 90.1 percent; beta-cellulose, 6.6 percent; gamma-cellulose, 3.3 percent. Increases in acidity and copper number occurred in most cases during the 8-year storage, but showed little relation to the initial quality of the papers.

As mentioned in the previous reports, these papers are not representative of the average quality of such papers of current manufacture. With the better knowledge developed during the past several years of the factors which affect the strength and stability of papers, and of technique for controlling these factors in the manufacturing processes, considerable improvement in the quality of all grades of record papers has been effected.

\section{SUMMARY}

The results of retests of various grades of commercial record papers after a normal aging period of 8 years confirm the results of a retest of them made 4 years ago, in that:

1. The papers were grouped in the same relative order of stability by their retention of folding endurance during the natural-aging period and under accelerated aging by heating them for 72 hours at $100^{\circ} \mathrm{C}$. The agreement was better for the 8-year period than for the 4-year period.

2. Generally, the papers which showed high retention of folding endurance during the 4-year natural-aging period lost little folding endurance during the following 4 years, but the opposite is true of the less stable papers.

3. There was good correlation between the chemical properties of the papers and their stability. As found in many other Bureau studies, the more stable papers were characterized by a good condition of the cellulose, as indicated by a high alpha-cellulose content and a 
low copper number, and by a low or moderate degree of acidity. The rosin content proved to be of less importance.

At the end of the 8-year normal-aging period a further correlation with the accelerated aging test was found, in that appreciable decreases in alpha-cellulose and increases in copper number and acidity took place in the papers of low stability. This did not happen during the 4 years of normal aging. A further additional finding at the end of the 8-year period is that the cellulose of the more unstable papers has a high content of beta-cellulose. Other Bureau studies have shown that when the alpha-cellulose fraction decreases on accelerated aging of paper by heating there is a proportionate increase in beta-cellulose, very little change generally occurring in the gamma portion.

The recent tests of the papers were made by R. W. Carr and W. K. Wilson and this assistance is acknowledged by the author.

\section{REFERENCES}

[1] R. H. Rasch, A study of purified wood fibers as a papermaking material. BS J. Research 3, 469 (1929) RP107.

[2] B. W. Scribner, Permanence standards for printing and writing papers. Transactions of Am. Soc. Mech. Engrs. 52, No. 19 (August 1930).

J. O. Burton, Permanence studies of current commercial book papers. BS J. Research 7, 429 (1931) RP349.

[3] R. H. Rasch and B. W. Scribner, Comparison of natural aging of paper with accelerated aging by heating. BS J. Research 11, 727 (1933) RP620.

[4] H. F. Launer, Determination of the $\mathrm{pH}$ values of papers. J. Research NBS 22, 553 (1939) RP1205.

[5] H. F. Launer, Simplified volumetric determination of alpha, beta, and gamma cellulose in pulps and papers. J. Research NBS 18, 333 (1937) RP979.

H. F. Launer, Volumetric determination of alpha-, beta- and gamma-cellulose in pulps and in papers containing sizing, filler, and other materials. J. Research NBS 20, 87 (1938) RP1068.

[6] R. H. Rasch and G. O. Stone, Estimating stability of paper by heating. Paper Trade J. 95, No. 4, 28 (July 28, 1932).

[7] M. B. Shaw, G. W. Bicking, and M. J. O'Leary, A study of the relation of some properties of cotton rags to the strength and stability of experimental papers made from them. J. Research NBS 14, 649 (1935) RP794.

[8] M. B. Shaw and M. J. O'Leary, Study of the effect of fiber components on the stability of book papers. J. Research NBS 17, 859 (1936) RP949. See also reference [1].

[9] M. B. Shaw and M. J. O'Leary, Effect of filling and sizing materials on stability of book papers. J. Research NBS 21, 671 (1938) RP1149.

Washington, July 11, 1939. 